\title{
Clinical utility of clocortolone pivalate for the treatment of corticosteroid-responsive skin disorders: a systematic review
}

This article was published in the following Dove Press journal:

Clinical, Cosmetic and Investigational Dermatology

21 June 2012

Number of times this article has been viewed

\author{
Sanjay Singh* \\ Baldeep Kaur Mann* \\ Department of Dermatology \\ and Venereology, Institute of Medical \\ Sciences, Banaras Hindu University, \\ Varanasi, Uttar Pradesh, India \\ *Both authors contributed equally \\ to the article
}

\begin{abstract}
Clocortolone pivalate $0.1 \%$ cream is a class IV mid-strength topical glucocorticoid. After topical application the glucocorticoid achieves higher concentration in inflamed skin compared with normal skin. Furthermore, pharmacologic studies have shown that there is little systemic absorption of clocortolone pivalate and hence no adrenal suppression. Systematic review was performed to evaluate the efficacy and safety of the glucocorticoid. PubMed, the Cochrane Library, and individual websites of the top 20 dermatology journals were searched using a defined strategy. Following the selection criteria, eight clinical trials were selected, of which five were randomized controlled trials. The trials mainly included patients with atopic dermatitis and eczemas. Quality appraisal of randomized controlled trials was done using the Delphi list, which showed that the trials had weaknesses in several items. The results of the systematic review tend to show that clocortolone pivalate cream is generally effective with early onset of action and has a good safety profile in the treatment of these conditions. Further studies comparing this glucocorticoid with other glucocorticoids and treatments in steroid-responsive dermatoses are desirable.
\end{abstract}

Keywords: clocortolone pivalate, corticosteroid, glucocorticoid, systematic review

\section{Introduction}

Introduction of topical glucocorticoids for the treatment of skin diseases has led to marked improvement in outcomes in several conditions. Nowadays, topical glucocorticoids are the most frequently used topical preparations in dermatology. Their efficacy in skin diseases depends on their anti-inflammatory and antimitotic actions and their capacity to decrease the synthesis of connective tissue molecules, ${ }^{1}$ in addition to immunosuppressive actions. Use of these agents is common in eczematous dermatoses and also in many inflammatory dermatoses. Inherent responsiveness of skin diseases to topical glucocorticoids varies, and, consequently, diseases may be classified as highly responsive (flexural psoriasis, atopic dermatitis in children, seborrheic dermatitis), moderately responsive (psoriasis, atopic dermatitis in adults, nummular eczema, papular urticaria, lichen simplex), and minimally responsive (palmo-plantar psoriasis, nail psoriasis, dyshidrotic eczema, lupus erythematosus, lichen planus, insect bites). ${ }^{2}$

Glucocorticoids do not have direct antipruritic action but suppress the inflammatory component of the dermatoses, thereby indirectly alleviating itching such as in atopic dermatitis. $^{3}$
Correspondence: Sanjay Singh

C-23, Swastik Towers, Lanka,

Varanasi-221005, India

$\mathrm{Tel}+915422369102$

Fax+91 5422367568

Email sanjaye2@gmail.com 


\section{Pharmacology}

Clocortolone pivalate is the international nonproprietary name of the compound that is chemically 9 -chloro- $6 \alpha-$ fluoro-11 $\beta$, 21-dihydroxy-16 $\alpha$ methylpregna-1, 4-diene-3, 20-dione 21-pivalate (Figure 1). ${ }^{4}$ Clocortolone pivalate is available as a $0.1 \%$ cream for the treatment of skin diseases. The water-washable emollient cream base consists of purified water, white petrolatum, mineral oil, stearyl alcohol, polyoxyl 40 stearate, carbomer 934P, edetate disodium, and sodium hydroxide, with methylparaben and propylparaben as preservatives. ${ }^{4}$

Clocortolone pivalate has been classified as a class IV mid-strength subclass $\mathrm{C}$ (betamethasone type characterized by C16 methyl substitution) $)^{5}$ or as a low-potency glucocorticoid. ${ }^{6}$ The recommended frequency of application of clocortolone pivalate cream $0.1 \%$ is three times a day. ${ }^{4}$

A recent article has reported detection of three previously unknown impurities in a clocortolone pivalate bulk sample. ${ }^{7}$

Pharmacologic studies on clocortolone pivalate have shown the following characteristics: no evidence of contact sensitization by Draize sensitization studies, both in the absence and presence of ultraviolet light; no evidence of phototoxicity after application of clocortolone pivalate to both forearms after removal of the stratum corneum and irradiation with Wood's light; low potential to cause irritation after application to the skin for 21 days; 19 times greater concentration in inflamed skin than in normal skin in the in vivo studies, and 178 times greater in the in vitro studies; and absence of adrenal suppression after application

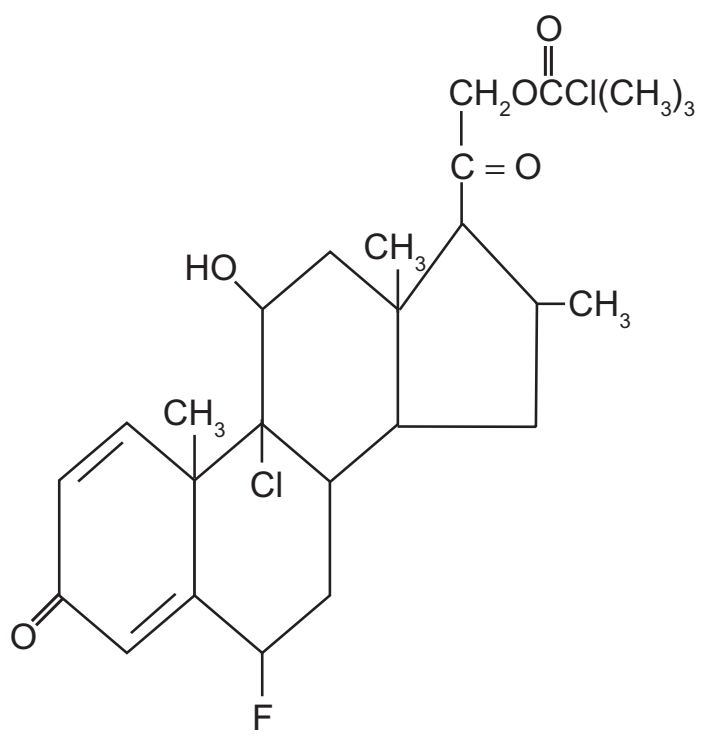

Figure I Clocortolone pivalate (chemical structure). ${ }^{4}$ of $30 \mathrm{~g}$ twice daily under occlusion for 21 days to ten human volunteers. ${ }^{8}$ It was concluded that after topical application, clocortolone is readily bioavailable for local activity in the skin but has little potential to enter the systemic circulation. ${ }^{8}$ Studies in rats have shown that after topical application most of the clocortolone remains at the site of application, with only $2 \%$ reaching the deep layers of the stratum corneum. ${ }^{8}$ As the only corticosteroid in the market with a pivalate group at the 21 position, ${ }^{9}$ the pharmacologic profile of clocortolone pivalate makes it eminently suitable for human use. ${ }^{8}$ The presence of both fluorine and chlorine ions and the absence of the 17 hydroxyl group in clocortolone pivalate may be responsible for its relative lack of adverse effects. ${ }^{8,10}$

\section{Efficacy and safety of clocortolone pivalate in the treatment of skin diseases}

We performed a systematic review of the efficacy and safety of clocortolone pivalate in the treatment of skin diseases. The published literature on the glucocorticoid was searched as follows.

\section{Search strategy}

The following databases were searched:

1. PubMed (http://www.ncbi.nlm.nih.gov/pubmed/) was searched for "clocortolone" in all fields without activating any limits.

Table I The Delphi list"

\begin{tabular}{lll}
\hline $\begin{array}{l}\text { Item } \\
\text { number }\end{array}$ & Item & Assessment \\
\hline Ia & $\begin{array}{l}\text { Treatment allocation: was randomization } \\
\text { performed? (i) Correct randomization } \\
\text { method described, (ii) inadequate } \\
\text { randomization method described, }\end{array}$ & \\
& $\begin{array}{l}\text { (iii) randomization stated but method } \\
\text { not described }\end{array}$ & \\
& Was the treatment allocation concealed? & Yes/no/unclear \\
Ib & Were the groups similar at baseline & Yes/no/unclear \\
2 & regarding the most important prognostic & \\
& indicators? & \\
3 & Were the eligibility criteria specified? & Yes/no/unclear \\
4 & Was the outcome assessor blinded? & Yes/no/unclear \\
5 & Was the care provider blinded? & Yes/no/unclear \\
6 & Was the patient blinded? & Yes/no/unclear \\
7 & Were point estimates and measures & Yes/no/unclear \\
& of variability presented for the primary & \\
& outcome measures? & \\
8 & Did the analysis include an intention-to- & Yes/no/unclear \\
& treat analysis? &
\end{tabular}




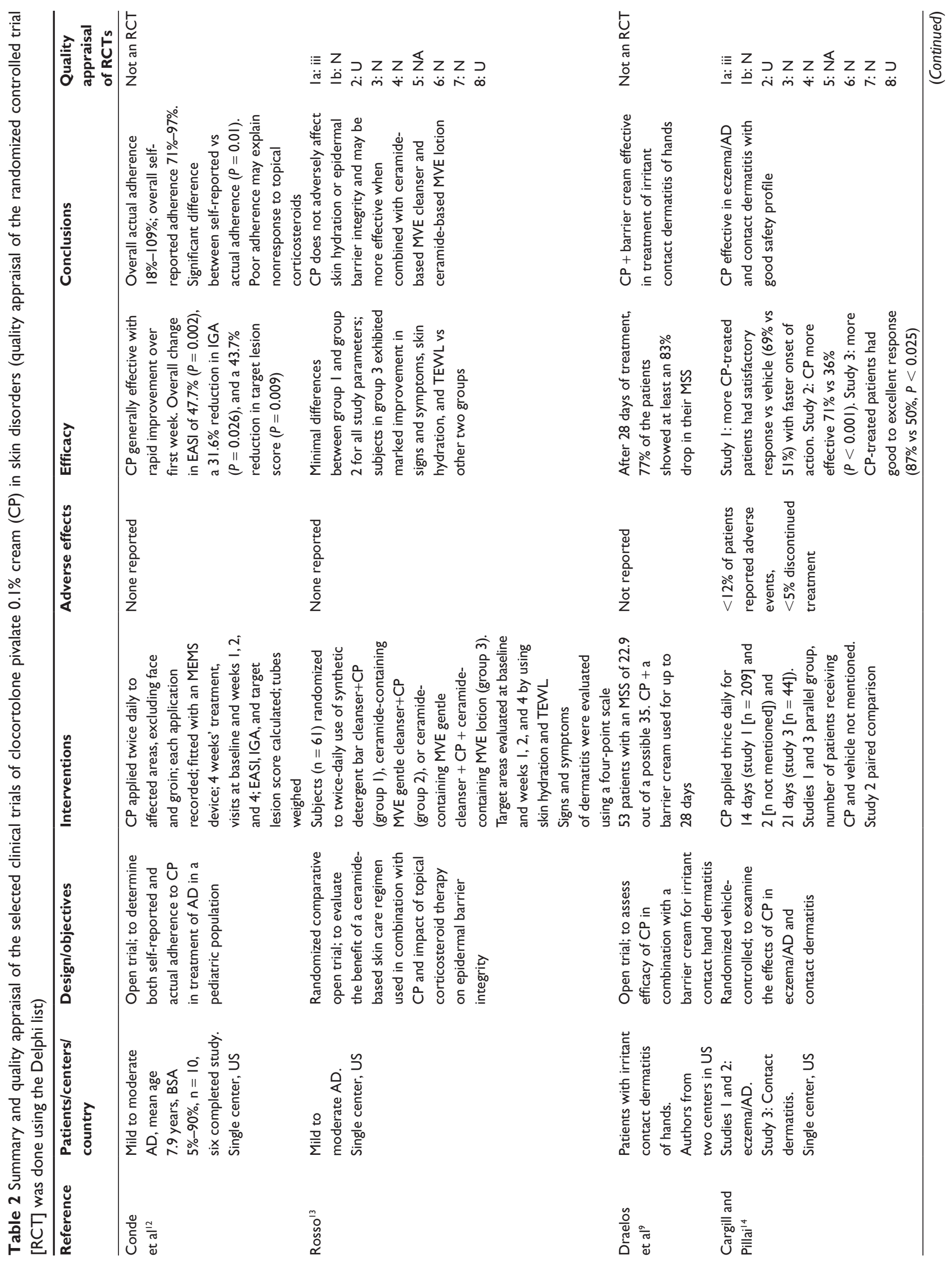




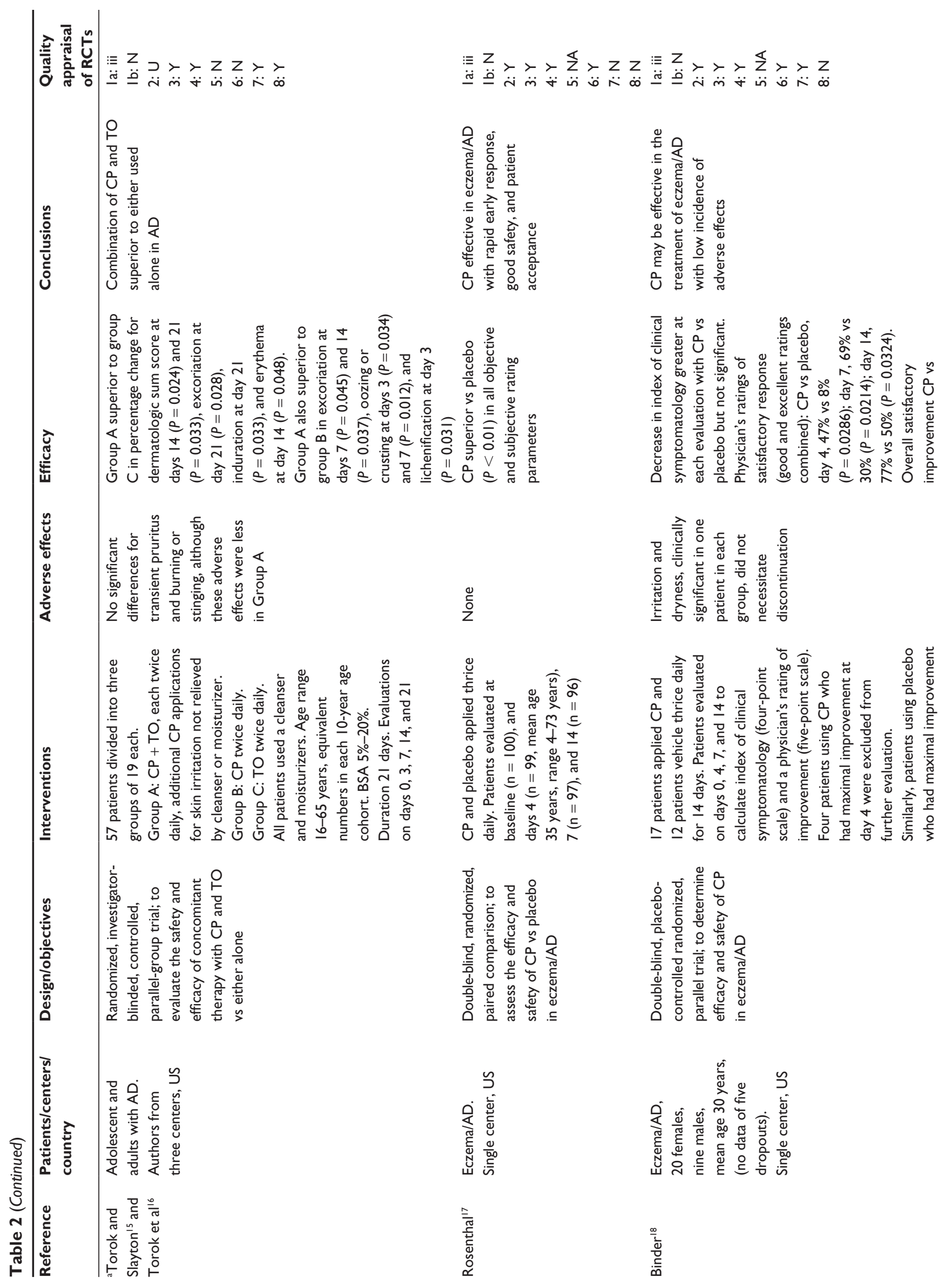


5
o
c
$\stackrel{0}{0}$
$z$
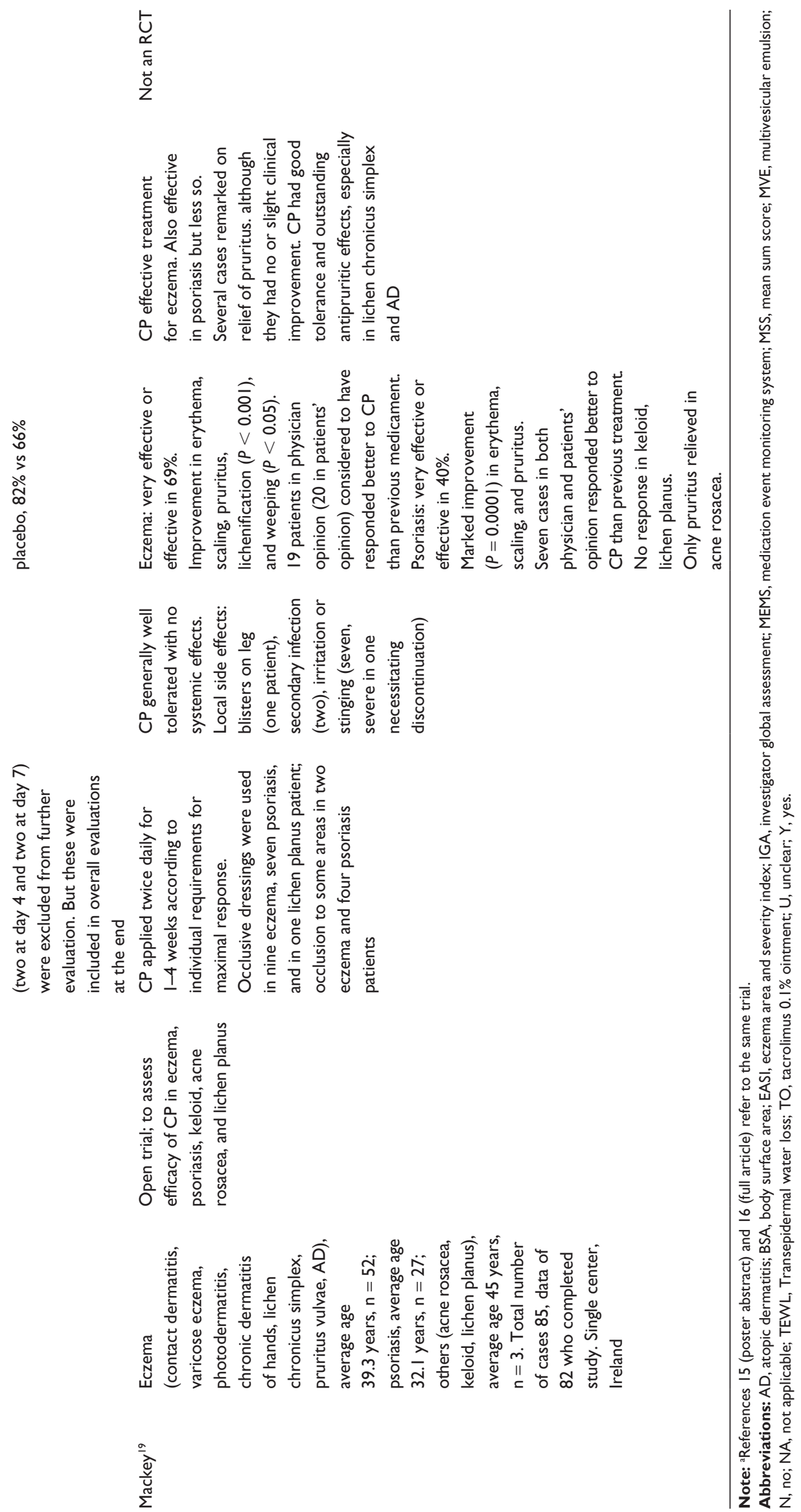
2. The Cochrane Library (http://www.thecochranelibrary. com/view/0/index.html) was searched for "clocortolone" in "search all text."

3. The top 20 dermatology journals were identified according to the current impact factors as available on http://impactfactor.weebly.com/dermatology.html. The websites of these journals were searched individually for "clocortolone."

The search was conducted on February 26, 2012. The full texts of all articles identified by this search were obtained, and then these were filtered through the following selection criteria for the purpose of evaluating the efficacy and adverse effects of clocortolone pivalate. The search was repeated on April 11, 2012, and the same results were obtained.

\section{Selection criteria}

Inclusion criteria were (1) clinical trial, (2) English language article, and (3) articles in other languages with English abstracts that contained sufficient information about methods and results. Exclusion criteria were (1) articles that referred to salts of clocortolone other than pivalate, and (2) review article.

\section{Data extraction}

After reading the full texts of the selected articles, the following variables were noted separately for each article: details of the patients, number of centers participating in the study, name of the country where the study was performed, trial design, objectives of the trial, interventions, adverse effects detected in the trial, efficacy, and conclusions.

\section{Quality appraisal}

Quality appraisal of the randomized controlled trials (RCTs) was done using the Delphi list (Table 1) ${ }^{11}$ The Delphi list was expanded in respect of item number 1a to give three options: (1) correct randomization method described, (2) inadequate randomization method described, and (3) randomization stated but method not described. These subcategories provided clarity about the way the randomization was performed in the trials. Treatment allocation concealment, which is considered to be the most important indicator of quality of a trial, was understood to have taken place only when there was a clear statement about it or when there was a statement that meant that treatment to be allocated was not known before the patient was entered into the study.

All articles that passed the selection criteria ${ }^{9,12-19}$ and those excluded by the selection criteria ${ }^{5,7,8,10,20-38}$ are mentioned in the list of references. Reasons for exclusion of the articles (nonfulfilment of inclusion criteria [IC] and/or fulfilment of exclusion criteria $[E C]$ ) are mentioned in parenthesis. The results of the systematic review are shown in Table 2.

A systematic search of the literature as explained previously identified one review article. ${ }^{10}$ This review article was excluded from the systematic review following the selection criteria. But this review article included results of nine studies; hence, it is being described here. Of the nine studies, two studies ${ }^{17,18}$ have been included in the systematic review; the remaining seven studies are unpublished. Results of the eight double-blind studies have been reviewed together in the article. ${ }^{10}$ In these studies, 297 patients were included (atopic dermatitis, 209; contact dermatitis, 44; seborrheic dermatitis, 44). The patients used clocortolone pivalate cream three times a day for 3 weeks and were evaluated weekly. The results showed the glucocorticoid to be significantly better than the vehicle. Several patients used the cream for up to 90 days. No adverse effects were noted, suggesting a good safety profile of the cream. The ninth unpublished study was a chronic use open study of 110 patients (psoriasis, 35; eczema/ atopic dermatitis, 66; other steroid responsive dermatitis, nine). The cream was applied for 3 weeks with an option of continuing for 210 days. The efficacy of clocortolone pivalate

Table 3 Conclusions with levels of evidence ${ }^{\text {a }}$ derived from the systematic review of clinical trials of clocortolone pivalate (CP)

\begin{tabular}{|c|c|c|}
\hline $\begin{array}{l}\text { Serial } \\
\text { number }\end{array}$ & Conclusion & $\begin{array}{l}\text { Level of } \\
\text { evidence }\end{array}$ \\
\hline I & $\begin{array}{l}\text { CP effective in eczema/AD and contact } \\
\text { dermatitis compared with vehicle with good } \\
\text { safety profile } 14,17,18\end{array}$ & 2 \\
\hline 2 & $\begin{array}{l}\mathrm{CP} \text { may be more effective when combined } \\
\text { with ceramide-based MVE cleanser and } \\
\text { ceramide-based MVE lotion }^{13}\end{array}$ & 2 \\
\hline 3 & $\begin{array}{l}\text { Combination of } \mathrm{CP} \text { and tacrolimus ointment } \\
\text { is superior to either used alone in } \mathrm{AD} \text {. No } \\
\text { significant differences among the groups for } \\
\text { transient pruritus and burning or stinging }{ }^{15,16}\end{array}$ & 2 \\
\hline 4 & $\begin{array}{l}\text { Actual adherence to treatment with } \mathrm{CP} \text { is } \\
\text { significantly less compared with self-reported } \\
\text { adherence }^{12}\end{array}$ & 4 \\
\hline 5 & $\begin{array}{l}\mathrm{CP} \text { along with barrier cream effective and } \\
\text { safe in treatment of irritant contact } \\
\text { dermatitis of hands } 9\end{array}$ & 4 \\
\hline 6 & $\begin{array}{l}\text { CP effective for eczema. Also effective in } \\
\text { psoriasis but less so. Outstanding antipruritic } \\
\text { effects, especially in lichen chronicus simplex } \\
\text { and AD. No systemic effects and mild local } \\
\text { adverse effects }\end{array}$ & 4 \\
\hline
\end{tabular}

Note: aOCEBM Levels of Evidence Working Group. The Oxford 201I Levels of Evidence. Oxford Centre for Evidence-Based Medicine. http://www.cebm.net/index. aspx?o = 5653 .

Abbreviations: AD, atopic dermatitis; MVE, multivesicular emulsion. 
was rated as good to superb, and a few patients noted mild dryness, which was attributed to the cream vehicle. This study suggested that the cream may be applied for long periods of time without development of significant delayed or cumulative local or systemic side effects. ${ }^{10}$

\section{Conclusion}

Clocortolone pivalate is a mid-potency topical glucocorticoid available as a $0.1 \%$ cream. Pharmacologic studies have shown that after topical application this glucocorticoid achieves higher concentration in inflamed skin than in normal skin, and that it has little potential to enter the systemic circulation and cause adrenal suppression. In the systematic review of its efficacy and safety for the treatment of skin diseases, eight clinical trials were selected, of which five were RCTs. The trials have mainly included patients with atopic dermatitis and eczemas. The main conclusions of the present systematic review along with the levels of evidence are mentioned in Table 3. Although the quality appraisal of RCTs showed weaknesses in several items, the results tend to show that clocortolone pivalate cream is generally effective and safe for the treatment of these conditions. Inadequate attention has been paid to detect the occurrence of systemic adverse effects in the clinical studies. Further studies comparing this glucocorticoid with other glucocorticoids and treatments in steroid-responsive dermatoses are desirable.

\section{Acknowledgment}

We thank Dr Akhil Maheshwari, Associate Professor of Pediatrics and Pharmacology, Chief, Division of Neonatology, University of Illinois at Chicago for help in obtaining the full texts of three articles.

\section{Disclosure}

The authors report no conflicts of interest in this work.

\section{References}

1. Brazzini B, Pimpinelli N. New and established corticosteroids in dermatology. Am J Clin Dermatol. 2002;3:47.

2. Valencia IC, Kerdel FA. Topical corticosteroids. Fitzpatrick's dermatology in general medicine. 7th ed. Wolff K, Goldsmith LA, Katz SI, Gilchrest BA, Paller AS, Leffell DJ, editors. New York: McGraw-Hill; 2008: 2102-2106.

3. Greaves MW. Pruritus. Rook's textbook of dermatology. 8th ed. Burns T, Breathnach S, Cox N, Griffiths C, editors. Chichester: Wiley-Blackwell; 2010:21.1-21.18.

4. Anonymous. Prescribing information. Cloderm cream $0.1 \%$. Available from: http:/www.clodermcream.com/ClodermCreamPI.pdf. Accessed March 13, 2012

5. Jacob SE, Steele T. Corticosteroid classes: a quick reference guide including patch test substances and cross-reactivity. J Am Acad Dermatol. 2006;54(4):723-727. (IC 1, EC 2)
6. Anonymous. Drugs for allergic disorders. Treat Guidel Med Lett. 2010;8(90):9-18. Available from: www.medicalletter.org. Accessed May 14, 2012.

7. $\mathrm{Xu} \mathrm{W,} \mathrm{Jia} \mathrm{X}$, Liu W, et al. Identification and characterization of three impurities in clocortolone pivalate. J Pharm Biomed Anal. 2012;62: 167-171. (IC 1)

8. Cargill I, Pillai R. The pharmacology and pharmacokinetics of clocortolone pivalate cream 0.1\% [Poster abstract P730]. J Am Acad Dermatol. 2005;52(Suppl 3):P73. (IC 1)

9. Draelos Z, Winston-Salem, Pillai R, Cargill I. Clocortolone pivalate cream in combination with a barrier cream in the control of irritant contact hand dermatitis [Poster abstract P806]. J Am Acad Dermatol. 2005;52(Suppl 3):P76.

10. Nierman MM. Safety and efficacy of clocortolone pivalate 0.1 percent cream in the treatment of atopic dermatitis, contact dermatitis, and seborrheic dermatitis. Cutis. 1981;27(6):670-671. (IC 1, EC 2)

11. Verhagen AP, de Vet HC, de Bie RA, et al. The Delphi list: a criteria list for quality assessment of randomized clinical trials for conducting systematic reviews developed by Delphi consensus. J Clin Epidemiol. 1998;51:1235-1241.

12. Conde JF, Kaur M, Fleischer AB Jr, Tusa MG, Camacho F, Feldman SR. Adherence to clocortolone pivalate cream $0.1 \%$ in a pediatric population with atopic dermatitis. Cutis. 2008;81(5):435-441.

13. Rosso JD. Evaluating the benefit of a ceramide-based skin care regimen used in combination with clocortolone pivalate $0.1 \%$ cream and the impact of topical corticosteroid therapy on epidermal barrier integrity [Poster abstract 612]. J Am Acad Dermatol. 2008;58(2 Suppl 2):AB51.

14. Cargill I, Pillai R. Clocortolone pivalate cream for the treatment of various dermatoses [Poster abstract P705]. J Am Acad Dermatol. 2005; 52(Suppl 3):P67.

15. Torok HM, Slayton R. Clocortolone pivalate cream $0.1 \%$ used concomitantly with tacrolimus ointment $0.1 \%$ in atopic dermatitis [Poster abstract P246]. J Am Acad Dermatol. 2004;50(Suppl 3):P65.

16. Torok HM, Maas-IrslingerR, Slayton RM. Clocortolone pivalate cream $0.1 \%$ used concomitantly with tacrolimus ointment $0.1 \%$ in atopic dermatitis. Cutis. 2003;72(2):161-166.

17. Rosenthal AL. Clocortolone pivalate: a paired comparison clinical trial of a new topical steroid in eczema/atopic dermatitis. Cutis. 1980;25(1): 96-98.

18. Binder RH. Clinical study of clocortolone privalate in the treatment of eczema/atopic dermatitis. Curr Ther Res Clin Exp. 1977;21(6): 796-801.

19. Mackey JP. Clocortolone, a new topical steroid in dermatoses. J Ir Med Assoc. 1973;66(6):157-159.

20. Lubach D, Hinz E. Development and regression of dermal corticosteroid atrophy. 1. Change in the skinfold thickness. Derm Beruf Umwelt. 1986; 34(5):146-149. (IC 3)

21. Anonymous. A new topical corticosteroid. Med Lett Drugs Ther. 1982; 24(623):103-104. (EC 2)

22. Kolb KH, Latza R, Hepp-Latza O, Lücker PW, Rindt W, Simon B. Human pharmacokinetic studies on penetration kinetics of a 6 alphaFluoro-9 alpha-chloro-16 alpha-methyl-delta 1,4-pregnadiene-11 beta-dihydroxy-3,20-dione-21-trimethyl-acetic acid (clocortolone trimethyl-acetic acid) after epicutaneous application. Arzneimittelforschung. 1978;28(9):1648-1651. (IC 3, EC 1)

23. Borelli S, Gartmann H, Klaschka F. Clocortolone ( $\mathrm{Cl} 68)$ versus fluocinolone, a double-blind, randomized lateral comparison. Hautarzt. 1973;24(7):294-297. (IC 3)

24. de Sevilla AF. Experiences with clocortolone in treating of skin diseases in hospital and ambulatory care. Med Welt. 1969;39:2142-2145. (IC 3)

25. Barry BW, Woodford R. Comparative bioavailability of proprietary topical corticosteroid preparations; vasoconstrictor assays on thirty creams and gels. Br J Dermatol. 1974;91(3):323-338. (EC 1)

26. Callen J, Chamlin S, Eichenfield LF, et al. A systematic review of the safety of topical therapies for atopic dermatitis. $\mathrm{Br} J$ Dermatol. 2007;156(2):203-221. (IC 1) 
27. Spergel JM, Boguniewicz M, Paller AS, et al. Addition of topical pimecrolimus to once- daily mid-potent steroid confers no shortterm therapeutic benefit in the treatment of severe atopic dermatitis; a randomized controlled trial. Br J Dermatol. 2007;157(2):378-381. (EC 1)

28. Del Rosso J, Friedlander SF. Corticosteroids: options in the era of steroid-sparing therapy. J Am Acad Dermatol. 2005;53(1 Suppl 1): S50-S58. (EC 2)

29. Norris DA. Mechanisms of action of topical therapies and the rationale for combination therapy. J Am Acad Dermatol. 2005;53(1 Suppl 1): S17-S25. (EC 2)

30. Kubota Y, Yoneda K, Nakai K, et al. Effect of sequential applications of topical tacrolimus and topical corticosteroids in the treatment of pediatric atopic dermatitis: an open-label pilot study. J Am Acad Dermatol. 2009;60(2):212-217. (EC 1)
31. Abramovits W. A clinician's paradigm in the treatment of atopic dermatitis. J Am Acad Dermatol. 2005;53(1 Suppl 1):S70-S77. (EC 2)

32. Subject index. J Am Acad Dermatol. 2004;50(Suppl 3):P188-P197. (IC 1)

33. Subject index. J Am Acad Dermatol. 2008;58(2 Suppl 2):AB173AB186. (IC 1)

34. Subject index. J Am Acad Dermatol. 2005;52(Suppl 3):P223-P232. (IC 1)

35. Gupta AK, Bluhm R. Seborrheic dermatitis. J Eur Acad Dermatol Venereol. 2004;18(1):13-26. (EC 2)

36. Index. Dermatologica. 1976;152(Suppl 1):265-271. (IC 1, EC 1)

37. Weber G. Perioral dermatitis, an important side-effect of corticosteroids. Dermatologica. 1976;152(Suppl 1):161-172. (IC 1, EC 1)

38. Barry BW. Bioavailability of topical steroids. Dermatologica. 1976; 152(Suppl 1):47-65. (EC 2)

\section{Publish your work in this journal}

Clinical, Cosmetic and Investigational Dermatology is an international, peer-reviewed, open access, online journal that focuses on the latest clinical and experimental research in all aspects of skin disease and cosmetic interventions. All areas of dermatology will be covered; contributions will be welcomed from all clinicians and basic science researchers globally. This journal is indexed on CAS. The manuscript management system is completely online and includes a very quick and fair peer-review system, which is all easy to use. Visit http://www.dovepress.com/testimonials.php to read real quotes from published authors. 